\title{
Complete endoscopic removal of colloid cysts: issues of safety and efficacy
}

\section{Charles Teo, M.D.}

Department of Neurosurgery, University of Arkansas for Medical Sciences, Little Rock Arkansas

The ideal management of colloid cysts is controversial. Treatment options include shunting procedures, stereotactic cyst aspiration, open craniotomy for microsurgical removal, and endoscopic removal. Although recent literature would suggest endoscopic removal is a reasonable approach, issues of safety and efficacy have dampened the universal acceptance of this surgical modality. The author performed a retrospective anaylsis to address these controversial issues.

The charts of all patients in whom endoscopic removal of colloid cysts was performed by the primary author at the University of Arkansas for Medical Sciences were reviewed. Eighteen patients underwent this procedure over the last 5 years. The mean patient age was 32 years, and the mean follow-up period was 32 months. In all patients complete tumor removal was macroscopically and radiologically confirmed, and there were no permanent deficits. Two patients suffered aseptic meningitis without long-term sequelae. There were no deaths and no incidence of tumor recurrence.

The results of this series support those previously published that underscore the advantages of endoscopic removal of colloid cysts. The procedure is safe and effective. Longer follow-up review is required to address the issue of duration of tumor-free survival.

Key Words * colloid cyst * endoscopy * third ventricle * hydrocephalus

Although endoscopy has been advocated as a reasonable surgical option for the removal of colloid cysts of the third ventricle, $[1,7-9,11,15,20]$ the technique remains controversial due to issues of safety and the ability to remove completely the cyst wall from the third ventricle, as well as the cost effectiveness in terms of operative time and the length of recovery period. The purpose of this study was not to compare endoscopic removal with other techniques; rather, it was designed to address these controversial issues by retrospective analysis.

\section{CLINICAL MATERIAL AND METHODS}

The charts of all patients who underwent endoscopic removal of an intraventricular tumor were reviewed. Only those patients who harbored colloid cysts of the third ventricle were included. Patients in whom an initial attempt at endoscopic removal had failed were also excluded. The list of patients is 
included in Table 1.

\begin{tabular}{|c|c|c|c|c|c|c|c|c|}
\hline & SUMMAR' & OF CASES, PRESENT & $\begin{array}{r}\text { TAE } \\
\text { SVMPTO }\end{array}$ & $\begin{array}{l}\text { E } 1 \\
5, \text { RADK }\end{array}$ & GRAPHIC F & ND INGS, AND & JTCOME* & \\
\hline $\begin{array}{l}\text { Case } \\
\text { No. }\end{array}$ & $\begin{array}{c}\text { Age [ys] } \\
\text { Sex }\end{array}$ & Symptorns & $\begin{array}{l}\text { Hydro- } \\
\text { cephalus }\end{array}$ & $\begin{array}{c}\text { Tumor } \\
\text { Size } \\
{[\mathrm{cm}]}\end{array}$ & $\begin{array}{l}\text { Operative } \\
\text { Time } \\
\text { [mins] } \\
\end{array}$ & $\begin{array}{c}\text { Cam- } \\
\text { plications }\end{array}$ & $\begin{array}{c}\text { Follow' } \\
\text { Up (mos) }\end{array}$ & $\begin{array}{l}\text { Recur- } \\
\text { rence }\end{array}$ \\
\hline 1 & $36, M$ & $\begin{array}{l}\text { visual obscuration, } \\
\text { headache }\end{array}$ & ++ & 3 & 186 & $\begin{array}{l}\text { aseptic me- } \\
\text { ningitis }\end{array}$ & 52 & no \\
\hline 2 & $28, F$ & headache & ++ & 3 & 87 & none & 50 & no \\
\hline 3 & 27, M & unconscious, EVD & +++ & 5 & & none & 50 & no \\
\hline 4 & $18, M$ & $\begin{array}{l}\text { headache, visual } \\
\text { obscuration }\end{array}$ & ++ & 2 & 120 & none & 50 & no \\
\hline 5 & 26 , M & $\begin{array}{l}\text { headache, "ind- } \\
\text { dental" }\end{array}$ & NV & 1 & 65 & none & 50 & no \\
\hline 6 & $25, M$ & "inciden tal" & $N V$ & $<1$ & 40 & none & 48 & no \\
\hline 7 & $38, F$ & $\begin{array}{l}\text { dromsiness, } \\
\text { womiting, head- } \\
\text { acheEVD }\end{array}$ & +++ & 2.5 & 135 & none & 47 & no \\
\hline 8 & $32, M$ & headache & + & 4 & $\dagger$ & none & 47 & no \\
\hline 9 & $30, F$ & headache & + & 1.5 & 60 & none & 46 & no \\
\hline 10 & $47, \mathrm{~F}$ & headache & + & 2 & 90 & none & 46 & no \\
\hline 11 & $21, M$ & $\begin{array}{l}\text { obtunded train- } \\
\text { stem dystunction, } \\
\text { EVD, poor STM }\end{array}$ & +++ & 3.5 & 117 & $\begin{array}{l}\text { tem porary } \\
\text { morsening } \\
\text { of STM }\end{array}$ & 39 & no \\
\hline 12 & $30, M$ & $\begin{array}{l}\text { headache, visual } \\
\text { obscuration }\end{array}$ & +++ & 2 & 68 & $\begin{array}{l}\text { aseptic me- } \\
\text { ningitis }\end{array}$ & 33 & no \\
\hline 13 & $20, F$ & headache & + & $<1$ & 55 & none & 31 & no \\
\hline 14 & $54, F$ & headache & NW & 1 & 60 & none & 25 & no \\
\hline 15 & $41, \mathrm{~F}$ & "inciden tal" & NV & 1.5 & 70 & none & 16 & no \\
\hline 16 & $38, F$ & headache & ++ & 1 & 27 & none & 14 & no \\
\hline 17 & $35, M$ & headache & + & $<1$ & 35 & none & 10 & no \\
\hline 18 & $29, M$ & headache & ++ & 2.5 & 120 & none & 10 & no \\
\hline 19 & $27, \mathrm{~F}$ & $\begin{array}{l}\text { visual otscur- } \\
\text { ation only }\end{array}$ & ++ & 3 & 85 & none & 8 & no \\
\hline 20 & $33, M$ & headache & ++ & 2 & 40 & none & 8 & no \\
\hline
\end{tabular}

"EVD = external ientricular drainage; $N V=$ no wentriculomegal $y_{1}$ STM $=$ short term memor $y_{1}+=$ mild ventriculomegaly; $++=$ moderate 'en triculomegal $y_{1}+++=$ se vere 'entriculomegal $y$ '

$\dagger$ failed; converted to o pen procedure.

Most patients had been seen by a neurosurgeon before referral, and three had undergone placement of external ventricular drains to treat acute clinical deterioration resulting from intracranial hypertension. In all patients pre- and postoperative computerized tomography scans or magnetic resonance images were obtained (Fig.1 and 2). 


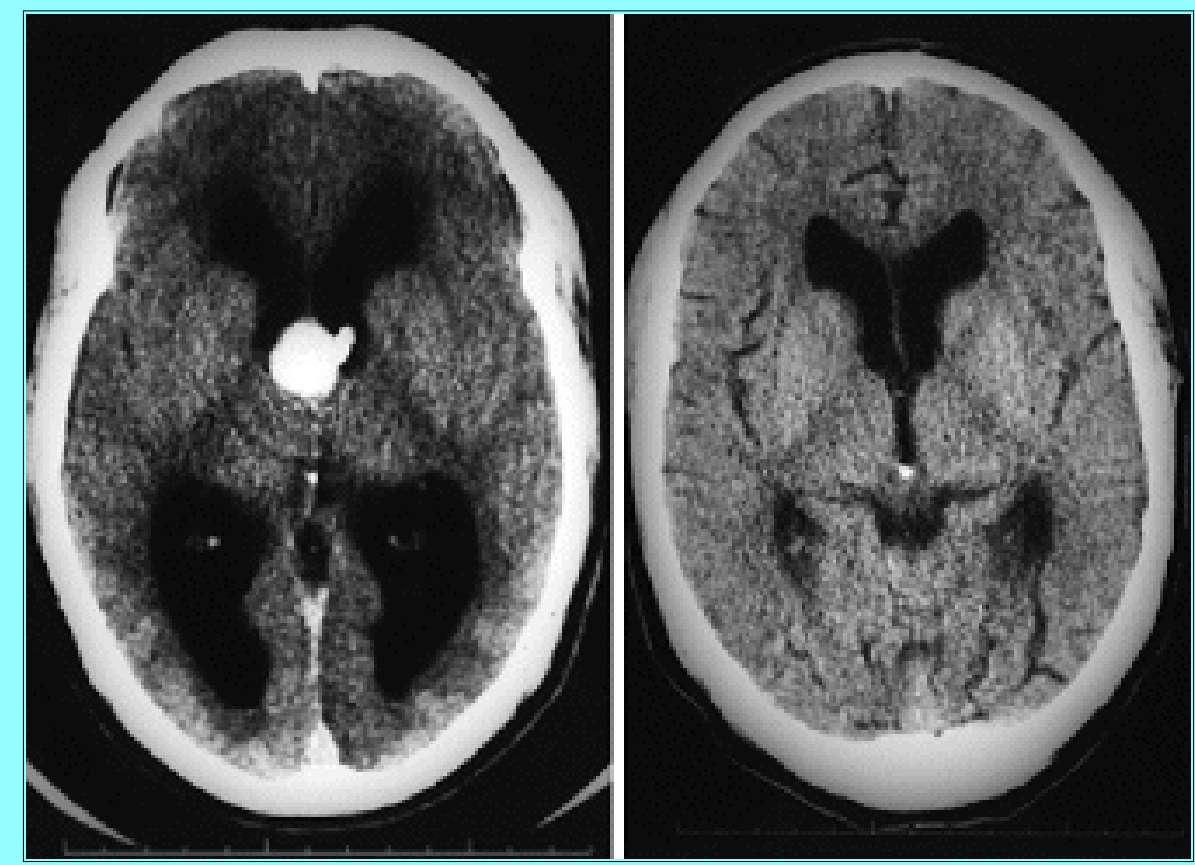

Fig. 1. Left: Preoperatively obtained computerized tomographic scan revealing a hyperdense colloid cyst that required bilateral external ventricular drainage. Right: Postoperatively obtained computerized tomographic scan demonstrating complete removal. In this case, computerized tomographic scan was more sensitive than magnetic resonance imaging.
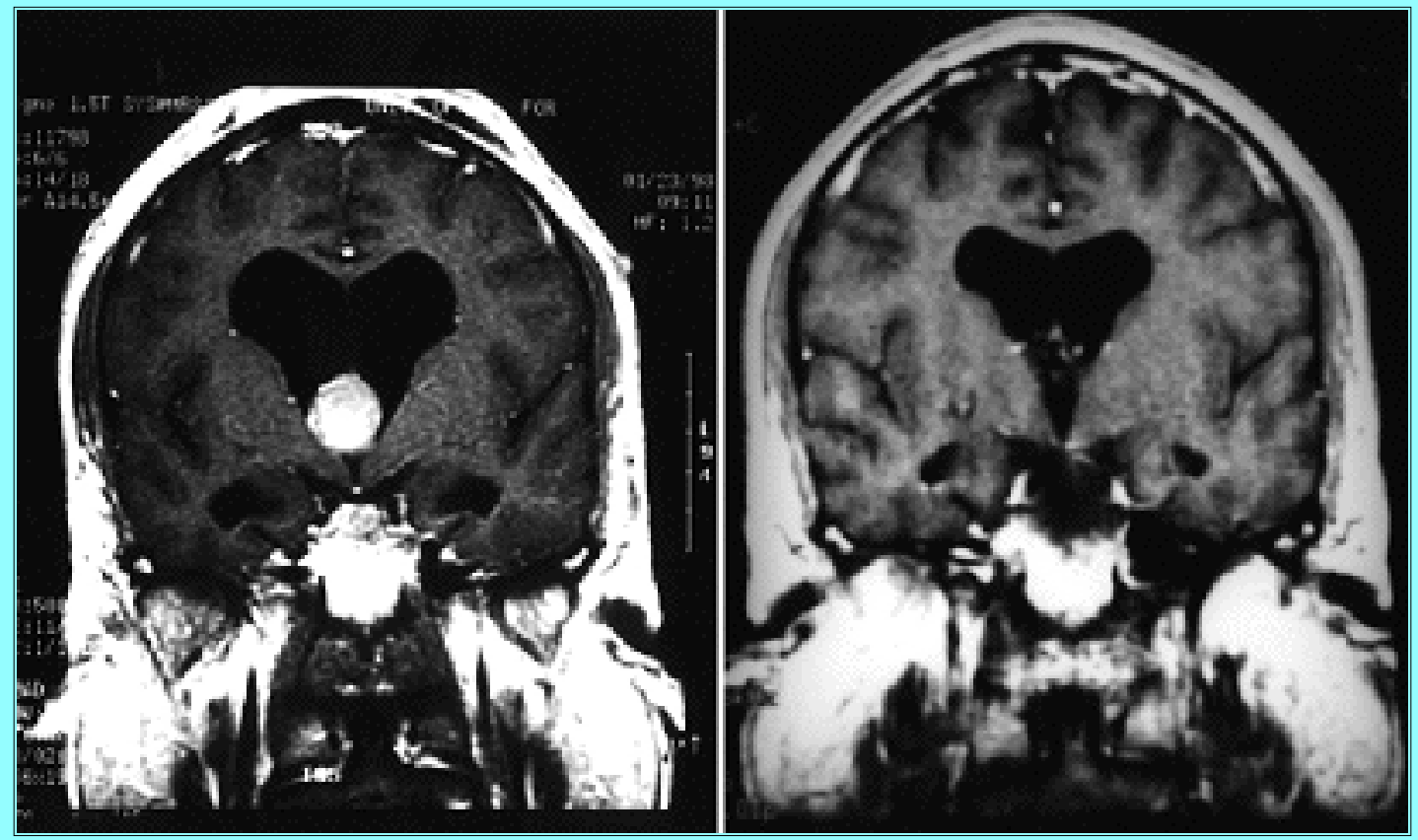

Fig. 2. Left: Preoperatively obtained coronal magnetic resonance image revealing a 2-cm colloid cyst. Right: Postoperatively obtained coronal magnetic resonance image demonstrating complete removal of cyst contents and wall.

Patients were informed of the options available: open craniotomy for a transcallosal or transcortical approach; stereotactic needle aspiration; endoscopic transcortical cyst removal; or various cerebrospinal fluid diversion procedures. All patients chose the endoscopic option, knowing that conversion to an open craniotomy was possible. The surgical technique is described in the next section (Video's 1 \& 2). Patients attended postoperative follow-up examinations at 6 weeks, 3 months, 6 months, and thereafter, once a year. 


\section{Surgical Technique}

The patient is placed in the supine position on the operating table with the head secured in three-point pin fixation. The neck is flexed approximately $45^{\circ}$ to the horizontal plane and neutral in the vertical plane. The burr hole is placed 5 to $6 \mathrm{~cm}$. from the midline and $11 \mathrm{~cm}$ behind the nasion on the nondominant side. Provisions should be made to convert the procedure into an open, transcortical approach if necessary. The lateral ventricle, if it is of normal size, is reached using stereotactic guidance. Otherwise, free-hand needle ventricular puncture is performed before the endoscope is introduced. We recommend a rigid $30^{\circ}$ endoscope of 2 to 5-mm outer diameter for best optical clarity. Once anatomical landmarks and the tumor are identified, the cyst is punctured and the contents evacuated. When the cyst contains inspissated, firm material, cup forceps are required to remove the contents in a piecemeal fashion.

\section{Click here to view Video 1.}

However, some of the larger cysts contain liquid of lower viscosity that can be evacuated through a catheter (Video 2). Care is taken to preserve the thalamostriate and septal veins, the fornix, and the choroidal vessels. If the tumor is large, the fornix stretched thinly over the cyst, and the foramen of Monro limited in size, then the cyst can be removed through the thinned-out fornix/septum pellucidum.

\section{Click here to view Video 2.}

The ipsilateral fornix may be sacrificed, if absolutely necessary, with no resulting postoperative memory disturbance, if the contralateral fornix is not damaged. Once the contents have been removed, gentle traction is placed on the cyst wall while the attached choroid plexus is fulgurated with either mono- or bipolar diathermy. Bleeding is controlled by using generous irrigation and diathermy. The tumor bed can be inspected using the $30^{\circ}$ or $70^{\circ}$ endoscope to ensure complete removal from the roof of the third ventricle. Conversion to an open microsurgical procedure is encouraged if bleeding is prohibitive, operative time prolonged excessively, or the cyst cannot be completely removed using endoscopic techniques alone. Prior to closure, the ventricle is irrigated generously to diminish the incidence of aseptic meningitis.

\section{RESULTS}

Twenty-six patients underwent endoscopic removal of intraventricular tumors over the last 5 years; 20 of these patients harbored colloid cysts of the third ventricle. In two patients the technique failed and necessitated conversion to an open transcortical craniotomy in a which standard microsurgical technique was performed. Outcome in these two patients was good, and there were no complications. The remaining 18 patients were between the ages of 18 and 54 years, and both genders were equally represented. Most patients presented with intermittent headache, although six patients experienced intracranial hypertension with sudden loss of consciousness or visual obscuration. One patient (Case 19) sustained intermittent loss of vision, papilledema, and ventriculomegaly but no headache. The mean operative time was 82.25 minutes (96.8 minutes for the first 10 cases and 67.75 minutes for the next eight). In all patients complete cyst removal was macroscopically and radiologically verified. In two patients analysis of findings from lumbar puncture at 5 and 7 days postop, respectively, resulted in a diagnosis of aseptic meningitis. Neither suffered long-term sequelae from this complication. One patient 
experienced temporary worsening of his short-term memory, but he presented obtunded with both severe hydrocephalus and sluggish pupils that may have accounted for the more stormy postoperative course. There were no cases of post-operative epilepsy in this series. All patients were discharged from the hospital by Day 3. The two patients in whom aseptic meningitis was diagnosed were readmitted 7 days and 5 days postop, respectively. Their symptoms resolved after receiving higher doses of dexamethasone.

All patients underwent postoperative MR imaging studies that demonstrated complete tumor removal. There has been no clinical or radiological recurrence in a mean follow-up period of 32 months (range 8-52 months).

\section{DISCUSSION}

There are very few subjects that evoke more debate than the ideal method of removing colloid cysts of the third ventricle. In 1983 Powell, et al.,[18] were the first to suggest endoscopic removal of colloid cysts. This was followed by several anecdotal cases confirming the ability to remove colloid cysts successfully.[4,7] In 1994 Lewis, et al.,[15] published a compelling series in which they compared endoscopic and microsurgical procedures for the removal of cysts, concluding that endoscopy was superior in terms of operative time and postoperative recovery. Since then many other studies have reinforced the advantages of the endoscopic technique. $[1,8,9,11,20]$ Despite these publications, this novel alternative has not gained widespread acceptance. The reasons for this are multifactorial. Neuroendoscopic procedures have a steep learning curve, and this procedure, in particular, requires advanced endoscopic skills. Colloid cysts are uncommon, and therefore, it is difficult to gain any significant experience unless one is part of a tertiary referral center. The necessity for complete removal of the cyst is, in itself, controversial.[13] Furthermore, at least a10-year follow-up period is mandatory before comments can be made about recurrence rates [16]. Most importantly, many authors believe that endoscopy offers very little over a limited transcortical, transventricular microsurgical approach.[14] The cortical incision is not much larger, the incidence of postoperative seizures is similar, and the ability to remove the cyst completely is, in fact, better. Finally, the interhemispheric, transcallosal removal of a colloid cyst is indisputably one of the most technically satisfying, rewarding operations in our armamentarium.

However, no surgical option is spared certain pitfalls. Cerebrospinal fluid-diversionary procedures include placement of bilateral ventriculoperitoneal shunts, bilateral Torkildsen's shunts, or a unilateral ventriculoperitoneal shunt combined with an endoscopic septum pellucidotomy. Although these are relatively simple and low-risk procedures, if the shunt malfunctions, the patient is at the same risk of sudden death as preoperatively. Stereotactic needle aspiration has been proposed as a low-risk, effective means of treating this condition. $[3,5,12,13,17,19]$ There are concerns, however, that some cysts cannot and should not be aspirated [13] and that leaving the cyst wall in place predisposes the patient to an unacceptably high risk of tumor recurrence.[10,16] Open microsurgical options include the interhemispheric, transcallosal approach in which the cyst is removed either through the expanded foramen of Monro or through an interforniceal technique. This carries all the risks inherent in a craniotomy in addition to those asscociated with splitting the corpus callosum, such as the hemiplegic/aphasic syndrome. Also, it remains controversial whether this approach provides adequate visualization of the roof of the third ventricle, from which these tumors are believed to arise. The microsurgical, transcortical, transventricular approach partially addresses this concern by providing a more lateral trajectory to the foramen of Monro and, therefore, a better look at the roof of the third ventricle. However, this requires a cortical incision of at least $2 \mathrm{~cm}$ and, like the transcallosal approach, 
still provides a limited view of the roof.

The results of this series illustrate the many advantages obtained in performing the endoscopic approach. The use of the endoscope did not result in any added complications. Rapid access to the tumor and closure after tumor removal limited operative time to a very reasonable duration. Bleeding, although a nuisance throughout stages of the procedure, did not result in any added deficit and was controlled in the majority of cases by using irrigation alone. Advances in technology have given us mono- and bipolar diathermy probes that can be passed down the working channel of the endoscope. Use of the angled endoscopes provided an excellent view of the roof of the third ventricle when the tumor was removed through the foramen of Monro, ensuring completeness of removal. This was confirmed by postoperative imaging studies. This same angle of view to the roof of the third ventricle is impossible when the operating microscope is used. Indeed, in the two cases that required conversion to an open craniotomy, the endoscope was utilized in the assessment of the completeness of tumor removal. There were no permanent complications or death in this series.

This series differs from recently published series in a number of ways. In agreement with the concept that complete tumor removal is mandatory, all attempts were made to achieve this end. If pure endoscopic techniques failed in this respect, then an open microsurgical approach, with endoscopic assistance, was performed. In addition, because the transcortical, microsurgical approach results in very few added deficits, there was a low threshold to convert. Despite this philosophy, conversion only occurred twice. Finally, a slitlike foramen of Monro did not preclude endoscopic resection of the tumor. Although the fornix was not sacrificed with impunity, large, posteriorly placed tumors that bulge into and thin out the fornix/septum pellucidum without expanding the foramen cannot be removed endoscopically or transcortically without performing partial sectioning the fornix/septum pellucidum. This philosophy did not add to the postoperative morbidity.

Although this is a significant series in number, it is limited in its longterm follow up. Complete tumor removal was achieved in all cases, but the issue of efficacy can only be answered fully if these patients remain tumor free for the next 10 to 15 years. However, the issue of safety has been addressed by this series. It appears that the endoscopic technique is at least comparable to the other techniques recently published $[1,8,12,13]$ and superior to results achieved in the microsurgical series that were published in the late 1980s.[2,6]

\section{CONCLUSIONS}

The use of endoscopy provides a safe, effective means of completely removing colloid cysts of the third ventricle. Comparative studies are difficult given the many variables associated with this disease and the different surgical options. Therefore, recommendations concerning the ideal operative technique cannot be made based on the results of this study alone. The surgeon's experience and preference, tumor size and consistency, longer follow-up periods, and honest reporting of complications will better guide the neurosurgeon in the future.

\section{References}

1. Abdou MS, Cohen AR: Endoscopic treatment of colloid cysts of the third ventricle. Technical note and review of the literature. J Neurosurg 89:1062-1068, 1998

2. Antunes JL, Louis KM, Ganti SR: Colloid cysts of the third ventricle. Neurosurgery 7:450-455, 1980 
3. Apuzzo MLJ, Clandrasoma PT, Zelman V: Computed tomographic guidance stereotaxis in the management of lesions of the third ventricular region. Neurosurgery 15:502-508, 1984

4. Auer LM, Holzer P, Ascher PW, et al: Endoscopic neurosurgery. Acta Neurochir 90:1-14, 1988

5. Bosch DA, Rahn T, Backlund EO: Treatment of colloid cysts of the third ventricle by stereotactic aspiration. Surg Neurol 9:15-18, 1978

6. Camacho A, Abernathey CD, Kelly PJ, et al: Colloid cysts: experience with the management of 84 cases since the introduction of computed tomography. Neurosurgery 24:693-700, 1989

7. Cohen AR, Shucart WA: Ventriculoscopic management of colloid cysts of the third ventricle, in Manwaring KH, Crone KR (eds): Neuroendoscopy. New York: Mary Ann Liebert, 1992, Vol 1, pp $109-117$

8. Decq P, Le Guerinel C, Brugieres P, et al: Endoscopic management of colloid cysts. Neurosurgery 42:1288-1296, 1998

9. Deinsberger W, Böker DK, Samii M: Flexible endoscopes in treatment of colloid cysts of the third ventricle. Minim Invasive Neurosurg 37:12-16, 1994

10. Donauer E, Moringlane JR, Ostertag CB. Colloid cysts of the third ventricle. Open operative approach or stereotactic aspiration? Acta Neurochir 83:24-30, 1986

11. Gaab MR, Schroeder HWS: Neuroendoscopic approach to intraventricular lesions. J Neurosurg 88:496-505, 1998

12. Hall WA, Lunsford LD: Changing concepts in the treatment of colloid cysts. An 11-year experience in the CT era. J Neurosurg 66:186-191, 1987

13. Kondziolka D, Lunsford LD: Stereotactic management of colloid cysts: factors predicting success. J Neurosurg 75:45-51, 1991

14. Kondziolka D, Lunsford LD: Stereotactic techniques for colloid cysts: roles of aspiration, endoscopy, and microsurgery. Acta Neurochir Suppl 61:76-78, 1994

15. Lewis AI, Crone KR, Taha J, et al: Surgical resection of third ventricle colloid cysts. Preliminary results comparing transcallosal microsurgery with endoscopy. J Neurosurg 81:174-178, 1994

16. Mathiesen T, Grane P, Lindquist C, et al: High recurrance rate following aspiration of colloid cysts in the third ventricle. J Neurosurg 78:748-752, 1993

17. Mohadjer M, Teshmar E, Mundinger F: CT-stereotactic drainage of colloid cysts in the foramen of Monro and the third ventricle. J Neurosurg 67:220-223, 1987

18. Powell MP, Torrens MJ, Thomson JLG, et al: Isodense colloid cysts of the third ventricle: a diagnosis and therapeutic problem resolved by ventriculoscopy. Neurosurgery 13:234-237, 1983

19. Rivas JJ, Lobato RD: CT-assisted stereotaxic aspiration of colloid cysts of the third ventricle. J Neurosurg 62:238-243, 1985

20. Teo C: Endoscopic neurosurgery, in Andrews RJ (ed): Intraoperative Neuroprotection. Baltimore: 
Williams \& Wilkins, 1996, pp 423-443

Manuscript received February 24, 1999.

Accepted in final form March 5, 1999.

Address reprint requests to: Charles Teo, M.D., Department of Neurosurgery, University of Arkansas for Medical Sciences, 4301 West Markham, Little Rock, Arkansas 72205. Email:

TeoCharles@exchange.uams.edu. 


\section{QuickTime Movies}
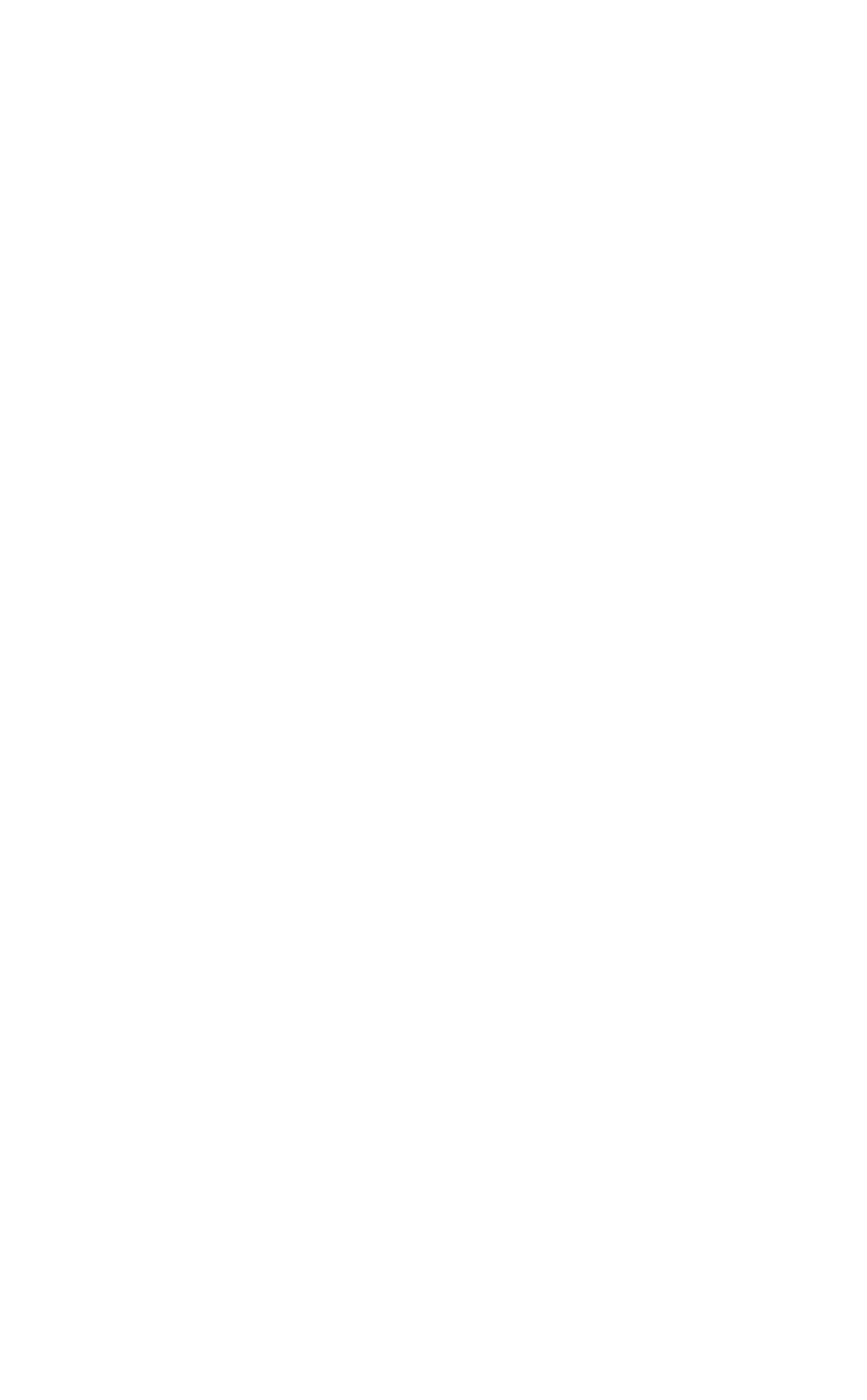